\title{
A review on potential toxicity of dental material and screening their biocompatibility
}

Shahriar Shahi, Mutlu Özcan, Solmaz Maleki Dizaj, Simin Sharifi, Nadin AlHaj Husain, Aziz Eftekhari \& Elham Ahmadian

To cite this article: Shahriar Shahi, Mutlu Özcan, Solmaz Maleki Dizaj, Simin Sharifi, Nadin AlHaj Husain, Aziz Eftekhari \& Elham Ahmadian (2019): A review on potential toxicity of dental material and screening their biocompatibility, Toxicology Mechanisms and Methods, DOI: 10.1080/15376516.2019.1566424

To link to this article: https://doi.org/10.1080/15376516.2019.1566424

Accepted author version posted online: 15 Jan 2019.

Submit your article to this journal $₫$

View Crossmark data $\nearrow$ 


\section{A review on potential toxicity of dental material and screening their}

\section{biocompatibility}

\section{Shahriar Shahi', Mutlu Özcan ${ }^{2}$, Solmaz Maleki Dizaj ${ }^{1}$, Simin Sharifi ${ }^{1}$, Nadin Al-Haj Husain ${ }^{3}$,} Aziz Eftekhari ${ }^{4,}$, Elham Ahmadian ${ }^{1,5, *}$

${ }^{1}$ Dental and periodontal research Center, Tabriz University of Medical Sciences, Tabriz, Iran.

${ }^{2}$ University of Zürich, Dental Materials Unit, Center for Dental and Oral Medicine, Clinic for Fixed and Removable Prosthodontics and Dental Materials Science.

${ }^{3}$ Specialization Candidate, Department of Reconstructive Dentistry and Gerodontology, School of Dental Medicine, University of Bern, Switzerland.

${ }^{4}$ Pharmacology and Toxicology Department, Maragheh University of Medical Sciences, Maragheh, Iran.

${ }^{5}$ Students' Research Committee, Tabriz University of Medical Sciences, Tabriz, Iran.

Short title: Biocompatibility and toxicity of dental materials

Word count: 3682 excluding references, tables and figures

\section{*Corresponding authors:}

*Aziz Eftekhari, Department of Pharmacology and Toxicology, Maragheh University of Medical Sciences, Maragheh, Iran. PO Box: 78151-55158 Email: ftekhari@ ymail.com

*Elham Ahmadian, Dental and Periodontal Research Center, Tabriz University of Medical Sciences, Tabriz, Iran. Tel: +98 (41) 33372250, E-mail: ahmadiane@tbzmed.ac.ir, ahmadian.elham@yahoo.com 


\begin{abstract}
Objectives: A wide range of compounds are utilized in dentistry such as dental composites, resins and implants. The successful clinical use of dental materials rely on their physiochemical properties as well as biological and toxicological reliability. Different local and systemic toxicities of dental materials have been reported. Placement of these materials in oral cavity for a long time period might yield in unwanted reactions. An extensive variety of materials is used in dentistry including filling materials, restorative materials, intracanal medicines, prosthetic materials, different types of implants, liners and irrigants. The increasing rate in development of the novel materials with applications in the dental field has led to an increased consciousness of the biological risks and tempting restrictions of these materials. The biocompatibility of a biomaterial used for the replacement or filling of biological tissue like teeth always had a high concern within the health care disciplines for patients. Materials and Methods: Any material used in humans should be tested before clinical application. There are many tests evaluating biocompatibility of these materials at the point of in vitro, in vivo and clinical investigations. Results: The current review discusses the potential toxicity of dental material and screening of their biocompatibility. Clinical Relevance: It is essential to use healthy and safe materials medical approaches. In dentistry, application of different material in long-term oral usage demands low or non-toxic agents gains importance for both patients and the staff. Furthermore, screening tests should evaluate any potential toxicity before clinical application.
\end{abstract}

Keywords: Biocompatibility; Toxicology; Oral health; Dentistry; Dental materials; Toxicity 


\section{Introduction}

There are some different descriptions for biocompatibility in the literature. However, in general it refers to the ability of a material to produce an suitable host response when applied as intended (Williams 1999). Evidently, biocompatibility can be defined as the compatibility of a material with a living tissue/system by not being toxic, harmful, physiologically reactive or including immunological rejection (Kirkpatrick et al. 1998; Black 2005). In addition, Based on biocompatibility (the reaction of the tissue to the used biomaterial), dental used biomaterials can be classified as biotolerant, bioinert and bioactive. The examples for these classes are summarized in Table 1.

An extensive variety of materials are used in dentistry including filling materials (such as composites, amalgam, polymeric monomers, cements), restorative materials, intracanal medicines, prosthetic materials, different types of implants (pure titanium, titanium alloys, zirconium), liners, irrigants, as well as mouthwash (such as antiseptic and anti-plaque rinse) (Vazifehasl et al. 2013; Dizaj et al. 2015; Parnia et al. 2017; Parnia et al. 2018). The increasing rate in development of the novel materials with dentistry applications has led to an increased consciousness of the biological risks and tempting restrictions of these materials. The biocompatibility of a biomaterial used for the replacement or filling of biological tissue like teeth always had a high concern within the health care disciplines for patients. On the other hand, dental staff are also at risk of adverse effects to the some biomaterials. With some biomaterials, the risks are even higher for staff than patients. For instance, dental resins or rubber products may result to adverse reactions to dental staff such as hand and fingertip reactions (Scott et al. 2004). Some reports have also shown generalized neuropathy after fourteen years of contact and exposure to methacrylates for dental staff (Sadoh et al. 1999).

Biological and immunological adverse reactions attributed to dental materials are infrequent and the reported side effects are not severe. However, this completely depends on the kind of the materials used and the technique used by 
staff. In some rare cases severe reactions have been published. Mjor reviewed the problems and benefits of dental restorative materials and their adverse effects. He emphasized that the allergic reactions are the most confirmed side effects to dental materials due to their known allergen components like transition metals and solutions such as formaldehyde (Mjör 1992). Formaldehyde may form as by-product of unreacted monomers from some dental resins that may lead to even enhanced tissue responses.

In general, dental materials are used for replacing damaged or defective dental tissues, and so, they should be chemically stable and inert for the oral cavity. However, as we know all materials show some degree of dissolution or degradation. Then, when the dissolved components from a material is toxic, the local or systemic reactions are probable. Therefore, due to the long-term utilization and durability of dental materials in the oral cavity as well as their contact or exposure with dental staff, there is a real need to ensure their biocompatibility. In this paper, a brief overview was performed on the toxicity and biocompatibility of different materials used in dentistry.

\section{Toxicity of dental materials}

Since dental materials are directly in touch with oral cavity, it's crucial to have a comprehensive understanding of the biocompatibility, toxicity and physiochemical properties of material used in dentistry. The plausible cytotoxicity of different dental materials will be presented below.

(KALLUS and MJÖR 1991). Dental amalgam is a mixture of liquid mercury and metal alloy that used in dentistry to fill cavities caused by tooth decay (Uçar and Brantley 2017). The cellular and molecular toxicities of mercury as the main component of amalgam is pietured in figure 1. Criticizers claimed that it has toxic effects that convert it to unsafe, both for the patient and staff. They argued that it perhaps show even more toxic effects for the dental staff operating it during a restoration (Mutter et al. 2005). The release of mercury from the restorative dental materials such as composites and amalgam can induce oral damages since it can diffuse into the tooth pulp and gingiva. It has been reported that mercury causes toxic effects in human gingival fibroblast (Reichl, Simon, et al. 2006). Also, it can inter into circulating blood after the uptake from saliva and cause toxicity in different organs. Mercury is known to be a 
neurotoxic and nephrotoxic agent (Hörsted-Bindslev 2004). Lobner et al, reported that amalgam causes neurotoxicity via the liberation of zinc in cortical cell culture, since the toxicity was inhibited by a zinc chelator (Lobner and Asrari 2003). In addition, long-time occupational exposure to mercury might cause subtle neurobehavioral effects in dental practitioners. Amalgam is also capable of inducing liver injury. It has been shown that incubation of rat hepatocytes with methyl mercury is simultaneous within the depletion of cellular glutathione reservoirs and leakage of liver enzymes aspartate aminotransferase (AST) and alanine aminotransferase (ALT) (Ashour et al. 1993).

Figure 1

Replacing the inorganic structure in dental tissue with resins is the initial purpose in application of adhesive systems (Peumans et al. 2005). The classification of adhesive systems were based on their link with smear layer whereas it is nowadays categorized according to the stages in clinical usage called total-etched and self-etched adhesive methods. Some dental adhesives are not polymerized, instead they are degraded and separated from resins and form free radicals which are provocative agents in induction of toxicity (Tadin et al. 2016).

Methacryloyloxy-dodecyl-pyridinium bromide as an important part of adhesive resins has been shown to trigger toxicity at high concentrations, although in lower concentration the antibacterial effects have been reported. Easy liberation of polymer followed by increased diffusion may stand for unwanted biological reactions (Van Landuyt et al. 2007; Cal et al. 2014). In addition, defective polymerization of free resin monomers and dissolutions with saliva or food intake within the first $24 \mathrm{~h}$ can give rise to cytotoxic effects on pulp tissue. Immunosuppression, mild to severe inflammation of pulp tissue and apoptotic cell death are the detrimental effects of adhesive resins previously reported (Moharamzadeh et al. 2007; Ahrari et al. 2010). For instance, bisglycidylmethacrylate (Bis-GMA), hydroxyethylmethacrylate (HEMA), urethanedimethacrylate (UDMA), triethyleneglycoldimethacrylate (TEGDMA) caused cytotoxicity in mouse fibroblasts after $24-72 \mathrm{~h}$ post exposure in which the mechanism of toxicity were mitochondrial malfunction and expression of inflammatory mediators (Reichl, Esters, et al. 2006). 
The cytotoxic free monomers are also appropriate surface for cariogenic microorganisms. It has been stated that these monomers stimulate the growth of cariogenic bacteria such as Streptococcus sobrinus and Lactobacillus acidophilus . Besides, TEGDMA promotes proliferation of Streptococcus mutans and Streptococcus salivarius. These microorganisms have vital role in dental caries and initiate cellular mechanisms involved in pulp damages and allergic reactions (Kleinsasser et al. 2006; Schweikl et al. 2006; Franz et al. 2009). Besides, resins result in the expression of cascades of proteins involved in the inflammatory reactions. This is in tight connection with allergic reactions such as eczema-like skin symptoms. In addition, high concentrations of these materials may display sub-acute and chronic toxicities which can show noxious effects in different body organs (Alanko et al. 2004; Demirci et al. 2008).

Oral soft tissue damages such as gingivitis are among the different reactions following the application of restorative materials. Regarding in vivo toxicity screenings of restorative materials, it is not unequivocally understood that the cytotoxicity is a result of materials or the bacterial plaque accumulated on the teeth (Walker 2004). The cytotoxicity related to cement usage has been shown to significantly decrease in time. This effect is attributed to the buffering impact of the saliva and present proteins (Schmid-Schwap et al. 2009). Moreover, similar results have been observed in the toxic effects of composites in fibroblasts in vitro which was shown to substantially decrease in aged composite models in artificial saliva (Goldberg 2008). However, some in vivo experiments pose the safety and biocompatibility of the applied composites. Ponce-Bravo et al examined the sub-chronic toxicity of commercial MEDENTAL Light-Cure Composite in rats. The results indicated that no cytological changes in microscopic and also hematological tests were observed (Ponce Bravo et al. 2011).

Although composite resin materials exhibit clinical advantages due to their physicochemical specifications, induction of some toxicities may constrict their application. In a study conducted by Şişman the cytotoxicity of five bulk fill composite resins, Filtek Bulk Fill, Tetric EvoCeram Bulk Fil, Sonic Fill, X-trafil and SDR were tested in human dental pulp stem cells. The results of this study showed that the viability of the cells in WST-1 assay was plunged during the incubation period (Şişman et al. 2016). 
In addition to the release of non-polymerized monomers, the presence of additives and fillers in dental composites have aroused some concerns. Bisphenol A (BPA) is considered to be one of these additives inducing toxicity (Fleisch et al. 2010). Due to the presence of BPA in food product, it is found in saliva even before using a dental composite (Downs et al. 2010). BPA is found as an impurity in dental resins and polymerize into solid after chemical or light exposure (SÖDERHOLM and Mariotti 1999). Inflammatory effects and toxicities due to BPA led researches to find its surrogates such as silorane based composites. However, some slight toxicities like ROS formation and cytokine release has been attributed to silorane (Krifka et al. 2012; Wellner et al. 2012).

Non-polymerized monomers released from dental resins prohibit cell proliferation and total polar lipid synthesis. The can even bind to unbound monomers which will mediate different cell metabolic events (Goldberg 2008). TEGDMA and HEMA can suppress heat shock protein expression in human monocytes (Noda et al. 2002). Also, TEGDMA gives rise to mitochondrial injuries (Lefeuvre et al. 2005). Zue et al, reported a novel mechanism associated in the toxicity of TEGDMA. This monomer stimulates autophagy via the activations of AMPK/mTOR pathway. Different feature of autophagy occurrence including formation of acidic vesicles and autophagy vacuoles and LC3-II accumulation was shown after TEGDMA exposure in human dental mesenchymal cells. $\mathrm{N}$-acetyl treatment could inhibit the autophagy and thus the toxicity of TEGDMA (Zhu et al, 2015).

In summary the mechanism of toxicity have been proposed to be related to short-term release of free monomers as well as long-term liberation of leachable components as a result of degradations over time. Additionally, ion release and growth of microorganisms in the interfacing location of teeth and dental materials are involved in the tissue damages occurring in situ. Productions of reactive oxygen species and depletion of cellular glutathione reservoirs are molecular mechanisms of probable pulp and gingival apoptosis implicated in resin monomers and also restorative material based-toxicities. Some additives to dental resins are potential substrates for cariogenic bacterial strains which can lead to subsequent secondary caries and degradation of the polymers lasting in the failure of the restoration 
(Goldberg 2008). Figure 2 illustrates the possible influence of these monomers in cell function and metabolism (Schmalz 2009).

In spite of the widespread use of alloys as casting materials, their toxicological profile is not comprehensively determined yet. Controversial results have been obtained after several tests studying their biological safety (Al-Hiyasat et al. 2002). The application of nano-silver materials in accordance with dental alloys has gained increasing momentum at the same time since they possess both antimicrobial and anti-inflammatory properties (Hamouda 2012). However, silver nanoparticles have been reported to induce cytotoxicity via interfering with different signalling pathways (García - Contreras et al. 2011). A novel 3D culture in LOD2 cells which resemble an in vivo-like environment assessed the toxicity of dental castings coated with silver nanoparticle. Cell viability tests revealed the materials have a time-dependent toxicity (Zhao et al. 2018).

Moreover, other metal-based alloys such as Cu-based alloy (Thermobond), Ni-Cr alloys (Remanium CS, Heranium NA, Wiron 99, CB Soft) and Co-Cr alloy (Wirobond C) used commercially have been stated to cause toxicity in vitro in which $\mathrm{Cu}$ ions have more detrimental effects in cell viability. However, Bioherador $\mathrm{N}$ alloy had meaningfully less cytotoxicity than the other ones (Al-Hiyasat et al.2003).

There are other dental materials which cause toxicity needing cautions prior usage. For instance, in paediatric dentistry, eugenol combined with zinc oxide which is a root canal sealer in pulpectomy has been reported to induce toxicity (Hui-Derksen et al. 2013). Also, in combination with carvacol and thymol is used to prohibit the proliferation of fungal infections (Markowitz et al. 1992; Mutoh and Tani-Ishii 2011; Vera et al. 2012). Disruption of cellular plasma membrane, interfering with ion homeostasis and induction of oxidative stress are the proposed mechanisms implied with eugenol application (Khan et al. 2011; Roberts et al. 2014). Furthermore, eugenol has been reported to induce antiplatelet activity through inhibition of cyclooxygenase 2 enzyme in human (Raghavendra and Naidu 2009). Eugenol, in a concentration dependent manner, is capable in cytotoxicity induction in dental pulp fibroblasts of primary teeth (Escobar-García et al. 2016). 
Replacement of missing teeth via implants, have made them reliable treatment surrogate in dentistry (Albrektsson et al. 1988). The physical and chemical properties of implant material should encompass well biocompatibility, resistance and strength specifications (Parr et al. 1985; Smith 1993). In addition to implants, there are several materials used for implant coatings which affect the efficiency of clinical application. These materials should also be examined for any toxic effects to obtain successful impacts in practice (Osman and Swain 2015).

In a study conducted by Reigosa et al, the cytotoxicity and genotoxicity of current titanium based-implants was investigated in osteoblast cells. According to the results of neutral red uptake test, alkaline phosphatase enzyme activity and lysosomal stability tests no significant cytotoxicity was reported in the applied implants. Also comet assay outcomes did not encounter any genotoxicity (Reigosa et al. 2008). However, a systematic toxicity assessment at every stage of testing, through in vitro to in vivo, is critical to warrant a longer implant lifetime (Thrivikraman et al. 2014).

Titanium and zirconium are known as inert dental materials. However, some earlier studies have recognised the potential hematologic and metabolic toxicity regarding to these materials. Furthermore, it seems probable that the occurrence of allergic or toxic reactions to titanium or zirconium implants may be under testing and has not been reported due to a lack of recognition as a possible etiological factor in implant failure. Some reports have shown that cationic form of titanium is relatively non-toxic in the amounts and forms that are normally ingested. Even so, when these metals are used as oral implants, they may form an oxide layer with exposing to oral fluid. Therefore, the formed titanium dioxide $\left(\mathrm{TiO}_{2}\right)$ or zirconium dioxide $\left(\mathrm{ZrO}_{2}\right)$ can act a boundary at the interface between the oral medium and the metal structure (Özcan and Hämmerle 2012; Chaturvedi T 2013). Any separation of the oxide layer may lead to corrosion of these metals and release of them into oral cavity (Chuang et al. 2005; Chaturvedi 2009; Chaturvedi TP 2013). Besides, this process may also cause to collection of titanium/zirconium ions in tissues especially local lymph nodes, and pulmonary tissue. Collection of titanium particles inside the macrophage lysosomes have reported to show hypersensitivity reactions (Mitchell et al. 1990). In an implant failure study by Frisken et al, two implants egress 
without any infection, and the existence of titanium in the lungs was observed to be 2.2-3.8 times higher than normal (Frisken et al. 2002).

Coating of bioinert materials with ability to encourage osseointegration on the titanium implant surfaces in order to improve the stability of them has been reported by different investigators (Samiei et al. 2016; Parnia et al. 2017). Based on the related literature, different types of biomaterials have used as particle coatings to the dental implant surface to progress soft tissue integration and therefore enhance dental implants success. In recent years, that types of nanoparticles with ability to induce a chemical bond with bone to advantage an ideal biological fixation are applied as coating of dental implants. Indeed, investigators attempt to improve bone incorporation of dental implants using nanoparticles as dental implant coatings. However, the same properties of nanoparticles that may progress the functionality may also display some unknown adverse effects, such as instability because of nano-coating or cellular nano-toxicity. The understanding of probable cellular effects and toxicity of nanoparticles as well as their environmental effects is necessary in this regards (Eftekhari et al. 2018).

The implant insertion may also expose in risk to bacterial plaque (Samiei et al. 2016; Parnia et al. 2017). The reports have shown that dental implants are at an enlarged risk of microbial contamination due to continuously colonization of microorganisms in the oral cavity. Furthermore, owing to the limited blood supply of peri-implant tissues as well as the lack of periodontal space at the implant-tissue interface, susceptibility of infection is increased in the interface (Derks and Tomasi 2015). The formation of infection is introduced by oral streptococci and followed by other microorganisms (Belibasakis 2014). Then, it slowly leads to accumulation of anaerobic bacteria (Koyanagi et al. 2010) that may cause the resorption of circumfluent bone and so may result in implant failing (Romanos and Weitz 2012). Nanoparticles have also recognized as one of the most effective antibacterial agents in different fields. Surface modification of titanium using antibacterial possessions of metal nanoparticles can decrease the number of bacteria and positively show more helpful clinical treatments. However, the unknown cellular effects of them are yet in challenge. Coating of implants by metal and metal oxide nanoparticles may leads to toxicity at higher concentrations of them due to ion 
release process. This outcome can be high risk both for patient and staff (Dizaj et al. 2014). In addition to patients, the workers who most likely come into contact with dental nanomaterials in the production, research, and development are in the risk of nanomaterial's toxicity. Nanomaterials may introduce to the staff body through inhalation as most of the dental nanomaterials were directly applied in the oral cavity or maxillofacial region. Besides, nanomaterials may also enter with the use of dental tools. Therefore, dental staff and patients may face nanomaterials directly throughout a grinding or polishing procedures. The body entered nanomaterials then may enter into the bloodstream (or lymph fluid) via absorption through oral mucosa. They may also enter through the digestive tract after swallowing. They can be distributed to different organs (liver, spleen, kidneys, heart, lungs, and brain) by systematic pathway. They may also directly translocate to the brain via nerves (Feng et al. 2015).

\section{Allergic reactions}

Non-biocompatible dental materials might cause different tissue responses, such as local or systemic toxicity and hypersensitivity reactions. Allergic reactions as alarming common public health problems are daily increasing in patients using different materials since they remain in the oral cavity for a long time (Ditrichova et al. 2007).The first reported allergic reaction occurred in amalgam application in 1928 (Fleischmann 1928). The extent of allergic reactions might be low with clinical manifestations such as urticarial, rash and swelling. However, it can cause life threatening side effects based on the importance of the issue effected (Karabucak and Stoopler 2007). In the oral cavity T-cell-mediated hypersensitivity reactions can result in mucosa damage, stomatitis and cheilitis (Ditrichova et al. 2007). Search of literature reveals that amalgam has a robust causative role in induction of toxicity leading to oral lichenoid reactions in comparison to other materials (SyeD et al. 2015). Due to the raised number of patients with allergies it is important to have adequate knowledge in this issue.

Regarding the resin-based materials, skin and mucosal reactions have been reported (Hume and Gerzina 1996). Eczema and skin symptoms occur at about $12 \%$ in patients and $27 \%$ dentists using these materials (Hensten-Pettersen 1998). Incomplete formation of the cross-linked polymer matrix from the dimethacrylate resin monomers lead to the 
liberation of non-polymerized monomers such as 2- HEMA and triethylene glycol methacrylate (TEGMA). These monomers have been implicated in the allergic effects of dental resins. Dermatosis has been reported to be the most frequent allergic response (Goldberg 2008). An in vivo study in guinea pig has shown that HEMA induces dermatitis, irritation and hypersensitivity (Katsuno et al. 1998). Glass ionomer cements and composites stimulate the lichenoid reactions, since they can surge the density of mast cells in oral cavity (Goldberg 2008). Dental cast alloys which release metal ions to the oral environment might produce allergic reactions. However, some other mechanisms including the promotion of bacterial adherence are also involved in adverse oral reactions related to cast alloys (Schmalz and Garhammer 2002).

Allergic response to implants arises from the metal ion release or from implant corrosion procedure. The released ions may lead to complex formation with proteins and as allergens producing hypersensitivity responses (Hallab et al. 2001). The allergic reaction that have observed with titanium implants include edema, redness, urticaria, eczema and pruritus of the skin or mucosa (Hallab et al. 2001). It has also reported that the risk of titanium allergy in patients who show sensitivity to other metals is more predominant. The allergic reactions related to implants have observed to display more serious problems in some cases with the signing of atopic dermatitis, impaired healing of fractures, pain, necrosis, and tolerance that leads to failing of implant (Thomas 2000).

\section{Genotoxicity}

Induction of DNA damage via an agent is referred to the genotoxic effects of the chemical. Due to the reciprocal relationship between genotoxicity and carcinogenesis, it is necessary to clarify the potential genotoxic effects of dental materials for both patients and staff health care. Dental materials have been categorized as medical products since 1995. Thus, it is crucial according to national and international guidelines that medical devices - either lately developed or currently in practice - have been confirmed for their biocompatibility and toxicological profile.

Genotoxicity is among the important adverse effects of chemicals. As most dental materials liberate small amounts of several elements into the oral cavity, proper regulations have to guarantee that the concern about the probable 
genotoxicity/mutagenicity of dental materials is obliterated or at least minimized. For instance, the European Standard "Biological evaluation of medical devices, Part 3: Tests for genotoxicity, carcinogenicity and reproductive toxicity" (EN 30993-3, ISO 10993-3:1992) mentions approaches to examine the genotoxicity of chemicals (Heil et al. 1996). In addition to the American Dental Association (ADA) as Specification No. 41 and by the Fédération Dentaire Internationale (FDI) as Technical Report No. 9, more specified standards were developed are existent virtually worldwide today and genotoxicity the is second most important test program in dental materials (Lyapina et al. 2015; Schmalz and Galler 2017).

It is worth to include again that many of these materials remain for long periods in the mouth. The genotoxic effects of distinct dental material like bleaching agents is vivid, since it contains hydrogen peroxide. The occurrence of oxidative stress via the increment of oxidizing agents intimately induces DNA damage and mutations (Ahmadian et al. 2017; Ribeiro DA et al. 2017). The commercial products of dental bleaching agents have been shown Genotoxicity in Chinese hamster's ovary and mouse lymphoma cells (Ribeiro D et al. 2005; Ribeiro DA et al. 2006). Also, toothpastes comprising whitening agents have been proved to exert genetic damages in human gingival cells (Camargo et al. 2014). Dental restorative materials such as bisphenol A has been capable of production of DNA adducts via comet assay in different human cells in vitro (Huang et al. 2015; Huang et al. 2016). Exposure of experimental animals to methyl methacrylate has increased the number of micro-nucleated cells in bone marrow resulting in mutagenicity in vivo (Araújo et al. 2013). The latter can also produce DNA strand breaks in a dose dependent manner in murine macrophages ( $\mathrm{Li}$ et al. 2012). The protective role of antioxidants such as melatonin in reduction of the aforementioned genetic damages suggests the pivotal role of oxidative hazard in the mechanism of genotoxicity of dental materials (Blasiak et al. 2011; Lottner et al. 2013). Endodontics compounds have also been the subject of extensive studies in the context of genotoxicity in several in vitro experiments. However, more reliable usage and clinical tests will provide a roadmap for future dentistry.

\section{Screening Methods}


Selection of biocompatible materials adoptable with pulp and other live tissues with minimal cytotoxic effects is an important issue in dentistry and medicine. Possessing no or very few deleterious effects on oral tissue is the definition of biocompatible dental material.

Dental materials must be assessed through several toxicity and biocompatibility steps before they could be used in clinic. Figure 2 illustrated the example of these tests at three steps. Biocompatibility assays will pinpoint the detrimental effects of materials, estimate the dose of chemicals released and survey the reactions to this dose.

Systematic approaches to estimate the bioavailability of newly produced materials are a part of toxicological evaluations in early stages of substance development. ISO standards due to their key role in meeting legal needs for premarketing biocompatibility assessments evaluate the toxicological profiles of materials/substances. Clinical risk assessments are carried out by means of ISO 14971 and ISO 10993-1. For instances, the instruction for the selection of the suitable techniques to test toxicity of medical devices which includes dental materials as well as the techniques themselves are presented in ISO 10993 series (Schmalz and Galler 2017). This standard encompasses 20 different parts ate the moment. In addition to this standard, ISO 7405 is especially developed for devices used in dentistry (Schmalz and Fan 2009). European regulation on registration, evaluation, and authorization of chemicals (REACH) has several legislations to have a high level of protection of human health for consumers, workers, and the environment. Also, the United States Food and Drug Administration (FDA) Center for Devices and Radiological Health regulates the dental materials and devices marketed in the United States in 3 classes. However, due to the certain restrictions in determining material biocompatibility through pre-clinical examinations, post marketing data should complete the picture through which dentist should report adverse effects.

The first step for evaluation of dental materials as in other chemicals is in vitro cytotoxicity tests. In addition to the usage of cell viability assays, there are some special terms in biocompatibility screening of dental materials. As mentioned in figure 2, in in vitro tests are used to estimate the plausible toxicity of dental materials. In direct cell contact assays, the material is directly placed onto cells in mono-layer cultures and dose-response curves are prepared 
after different incubation periods. However, these testing situations might not be clinically relevant, because the cells in the body are not in direct contact with the materials. So, indirect contact tests are designed in which there is a barrier between the cells and examined substances (Murray et al. 2007). The below assays use barriers to mimic the real situations.

In agar diffusion test, the test material is basically incubated on a layer of agar covering a monolayer cell culture where the diffusion of the substance through agar is used to determine the non-specific cytotoxicity of materials (Stanford 1980). In similar techniques Millipore filter is the surrogate of the agarose. However these two methods may not be the ideal test for imitating the oral environment. Dentin barrier tests via stimulating the in vivo oral cavity environment makes it a preferable cytotoxicity assay (Swetha et al. 2015).

In the next step, biological analysis depend on animal experimentation to a great extent. Before a dental material can be utilized in practice, it must always be assessed comprehensively in several species of laboratory animals to establish its local and systemic impact in the body (Rowan 1997). Moreover, in vivo tests help to anticipate the potential toxic risks that might be encountered in man. Some of these test have been mentioned in figure 3 .

Finally, the ideal methodology for biocompatibility evaluation is clinical tests in individuals. However, ethical and legal consideration may restrict this approach. Figure 3.

\section{Conclusion}

It is essential to use healthy and safe materials medical approaches. In dentistry, application of different material in long-term oral usage demands low or non-toxic agents gains importance for both patients and the staff. Furthermore, screening tests should evaluate any potential toxicity before clinical application.

\section{Acknowledgement}

The authors would like to thank Maragheh University of Medical Sciences for their moral support. 
Conflict of Interest: All authors including Shahriar Shahi, Aziz Eftekhari, Solmaz Maleki Dizaj, Simin Sharifi, Nadin

\begin{abstract}
Al-Haj Husain, Elham Ahmadian and Mutlu Özcan declare that they have no conflict of interest.
\end{abstract}
Funding: The work did not receive any fund.

\title{
References
}

Ahmadian E, Eftekhari A, Babaei H, M Nayebi A, A Eghbal M. 2017. Anti-Cancer Effects of Citalopram on Hepatocellular Carcinoma Cells Occur via Cytochrome C Release and the Activation of NF-kB. Anti-Cancer Agents in Medicinal Chemistry (Formerly Current Medicinal Chemistry-Anti-Cancer Agents). 17(11):15701577.

Ahrari F, Tavakkol Afshari J, Poosti M, Brook A. 2010. Cytotoxicity of orthodontic bonding adhesive resins on human oral fibroblasts. The European Journal of Orthodontics. 32(6):688-692.

Al-Hiyasat AS, Bashabsheh OM, Darmani H. 2002. Elements released from dental casting alloys and their cytotoxic effects. International Journal of Prosthodontics. 15(5).

Al-Hiyasat AS, Bashabsheh OM, Darmani H. 2003. An investigation of the cytotoxic effects of dental casting alloys. International Journal of Prosthodontics. 16(1).

Alanko K, Susitaival P, Jolanki R, Kanerva L. 2004. Occupational skin diseases among dental nurses. Contact dermatitis. 50(2):77-82.

Albrektsson T, Brånemark P, Hansson H-A, Kasemo B, Larsson K, Lundström I, McQueen DH, Skalak R. 1983. The interface zone of inorganic implantsIn vivo: Titanium implants in bone. Annals of biomedical engineering. 11(1):1-27.

Albrektsson T, Dahl E, Enbom L, Engevall S, Engquist B, Eriksson AR, Feldmann G, Freiberg N, Glantz PO, Kjellman O. 1988. Osseointegrated oral implants. Journal of periodontology. 59(5):287-296.

Araújo AMd, Alves GR, Avanço GT, Parizi JLS, Nai GA. 2013. Assessment of methyl methacrylate genotoxicity by the micronucleus test. Brazilian oral research. 27(1):31-36.

Ashour H, Abdel-Rahman M, Khodair A. 1993. The mechanism of methyl mercury toxicity in isolated rat hepatocytes. Toxicology letters. 69(1):87-96.

Belibasakis GN. 2014. Microbiological and immuno-pathological aspects of peri-implant diseases. Archives of oral biology. 59(1):66-72.

Black J. 2005. Biological performance of materials: fundamentals of biocompatibility. Crc Press.

Blasiak J, Kasznicki J, Drzewoski J, Pawlowska E, Szczepanska J, Reiter RJ. 2011. Perspectives on the use of melatonin to reduce cytotoxic and genotoxic effects of methacrylate-based dental materials. Journal of pineal research. 51(2): 157-162.

Cal E, Guneri P, Atay A, Cetintas VB. 2014. Cytotoxicity of dentin bonding agents. General dentistry.

62(6):e11-14.

Camargo S, Joias RP, Santana-Melo GF, Ferreira LT, El Achkar V, Rode Sde M. 2014. Conventional and whitening toothpastes: cytotoxicity, genotoxicity and effect on the enamel surface. Am J Dent. 27(6):307-311. Chaturvedi T. 2009. An overview of the corrosion aspect of dental implants (titanium and its alloys). Indian Journal of Dental Research. 20(1):91.

Chaturvedi T. 2013. Allergy related to dental implant and its clinical significance. Clinical, cosmetic and investigational dentistry. 5:57.

Chaturvedi TP. 2013. Allergy related to dental implant and its clinical significance. Clinical, Cosmetic and Investigational Dentistry. 5:57-61.

Chuang S, Cai T, Douglass C, Wei L, Dodson T. 2005. Frailty approach for the analysis of clustered failure time observations in dental research. Journal of dental research. 84(1):54-58.

Demirci M, Hiller K-A, Bosl C, Galler K, Schmalz G, Schweikl H. 2008. The induction of oxidative stress, cytotoxicity, and genotoxicity by dental adhesives. dental materials. 24(3):362-371. 
Derks J, Tomasi C. 2015. Peri-implant health and disease. A systematic review of current epidemiology. Journal of clinical periodontology. 42(S16).

Ditrichova D, Kapralova S, Tichy M, Ticha V, Dobesova J, Justova E, Eber M, Pirek P. 2007. Oral lichenoid lesions and allergy to dental materials. Biomedical Papers of the Medical Faculty of Palacky University in Olomouc. 151(2).

Dizaj SM, Barzegar-Jalali M, Zarrintan MH, Adibkia K, Lotfipour F. 2015. Calcium carbonate nanoparticles; potential in bone and tooth disorders. Pharmaceutical Sciences. 20:175.

Dizaj SM, Lotfipour F, Barzegar-Jalali M, Zarrintan MH, Adibkia K. 2014. Antimicrobial activity of the metals and metal oxide nanoparticles. Materials Science and Engineering: C. 44:278-284.

Downs JMZ, Shuman D, Stull SC, Ratzlaff RE. 2010. Bisphenol A blood and saliva levels prior to and after dental sealant placement in adults. American Dental Hygienists' Association. 84(3):145-150.

Eftekhari A, Dizaj SM, Chodari L, Sunar S, Hasanzadeh A, Ahmadian E, Hasanzadeh M. 2018. The promising future of nano-antioxidant therapy against environmental pollutants induced-toxicities. Biomedicine \& Pharmacotherapy. 103:1018-1027. Escobar-García M, Rodríguez-Contreras K, Ruiz-Rodríguez S, Pierdant-Pérez M, Cerda-Cristerna B, PozosGuillén A. 2016. Eugenol toxicity in human dental pulp fibroblasts of primary teeth. Journal of Clinical Pediatric Dentistry. 40(4):312-318.

Feng X, Chen A, Zhang Y, Wang J, Shao L, Wei L. 2015. Application of dental nanomaterials: potential toxicity to the central nervous system. International journal of nanomedicine. 10:3547.

Fleisch AF, Sheffield PE, Chinn C, Edelstein BL, Landrigan PJ. 2010. Bisphenol A and related compounds in dental materials. Pediatrics.peds. 2009-2693.

Fleischmann P. 1928. Zur Frage der Gefährlichkeitkleinster Quecksilbermengen1. DMW-Deutsche Medizinische Wochenschrift. 54(08):304-307.

Franz A, König F, Lucas T, Watts DC, Schedle A. 2009. Cytotoxic effects of dental bonding substances as a function of degree of conversion. Dental materials. 25(2):232-239.

Frisken K, Dandie G, Lugowski S, Jordan G. 2002. A study of titanium release into body organs following the insertion of single threaded screw implants into the mandibles of sheep. Australian dental journal. 47(3):214217.

García-Contreras R, Argueta-Figueroa L, Mejía-Rubalcava C, Jiménez-Martínez R, Cuevas-Guajardo S, Sánchez-Reyna PA, Mendieta-Zeron H. 2011. Perspectives for the use of silver nanoparticles in dental practice. International dental journal. 61(6):297-301.

Goldberg M. 2008. In vitro and in vivo studies on the toxicity of dental resin components: a review. Clinical oral investigations. 12(1):1-8.

Hallab N, Merritt K, Jacobs JJ. 2001. Metal sensitivity in patients with orthopaedic implants. JBJS. 83(3):428. Hamouda IM. 2012. Current perspectives of nanoparticles in medical and dental biomaterials. Journal of biomedical research. 26(3):143-151.

Heil J, Reifferscheid G, Waldmann P, Leyhausen G, Geurtsen W. 1996. Genotoxicity of dental materials. Mutation Research/Genetic Toxicology. 368(3-4):181-194.

Hensten-Pettersen A. 1998. Skin and mucosal reactions associated with dental materials. European Journal of Oral Sciences. 106(2 Pt 2):707-712.

Hörsted-Bindsley P, 2004. Amalgam toxicity —environmental and occupational hazards. Journal of dentistry. 32(5):359-365.

Huang FM, Chang YC, Lee SS, Yeh CH, Lee KG, Huang YC, Chen CJ, Chen WY, Pan PH, Kuan YH. 2016. BisGMA-induced cytotoxicity and genotoxicity in macrophages are attenuated by wogonin via reduction of intrinsic caspase pathway activation. Environmental toxicology. 31(2):176-184.

Huang FM, Kuan YH, Lee SS, Chang YC. 2015. Cytotoxicity and genotoxicity of triethyleneglycol-

dimethacrylate in macrophages involved in DNA damage and caspases activation. Environmental toxicology. 30(5):581-588.

Hui-Derksen E, Chen C-F, Majewski R, Tootla RG, Boynton JR. 2013. Retrospective record review: reinforced zinc oxide-eugenol pulpotomy: a retrospective study. Pediatric dentistry. 35(1):43-46.

Hume W, Gerzina T. 1996. Bioavailability of components of resin-based materials which are applied to teeth. Critical Reviews in Oral Biology \& Medicine. 7(2):172-179.

KALLUS T, MJÖR IA. 1991. Incidence of adverse effects of dental materials. European Journal of Oral Sciences. 99(3):236-240.

Karabucak B, Stoopler E. 2007. Root canal treatment on a patient with zinc oxide allergy: a case report. International endodontic journal. 40(10):800-807. 
Katsuno K, Manabe A, Kurihara A, Itoh K, Hisamitsu H, Wakumoto S, Yoshida T. 1998. The adverse effect of commercial dentine-bonding systems on the skin of guinea pigs. Journal of oral rehabilitation. 25(3):180-184. Khan A, Ahmad A, Akhtar F, Yousuf S, Xess I, Khan LA, Manzoor N. 2011. Induction of oxidative stress as a possible mechanism of the antifungal action of three phenylpropanoids. FEMS yeast research. 11(1):114-122. Kirkpatrick C, Bittinger F, Wagner M, Köhler H, Van Kooten T, Klein C, Otto M. 1998. Current trends in biocompatibility testing. Proceedings of the Institution of Mechanical Engineers, Part H: Journal of Engineering in Medicine. 212(2):75-84.

Kleinsasser NH, Schmid K, Sassen AW, Harréus UA, Staudenmaier R, Folwaczny M, Glas J, Reichl F-X. 2006. Cytotoxic and genotoxic effects of resin monomers in human salivary gland tissue and lymphocytes as assessed by the single cell microgel electrophoresis (Comet) assay. Biomaterials. 27(9):1762-1770.

Koyanagi T, Sakamoto M, Takeuchi Y, Ohkuma M, Izumi Y. 2010. Analysis of microbiota associated with peri-implantitis using 16S rRNA gene clone library. Journal of oral microbiology. 2(1):5104.

Krifka S, Seidenader C, Hiller K-A, Schmalz G, Schweikl H. 2012. Oxidative stress and cytotoxicity generated by dental composites in human pulp cells. Clinical oral investigations. 16(1):215-224.

Lefeuvre M, Amjaad W, Goldberg M, Stanislawski L. 2005. TEGDMA induces mitochondrial damage and oxidative stress in human gingival fibroblasts. Biomaterials. 26(25):5130-5137.

Li YC, Kuan YH, Huang FM, Chang YC. 2012. The role of DNA damage and caspase activation in cytotoxicity and genotoxicity of macrophages induced by bisphenol-A-glycidyldimethacrylate. International endodontic journal. 45(6):499-507.

Lobner D, Asrari M. 2003. Neurotoxicity of dental amalgam is mediated by zinc. Journal of dental research. 82(3):243-246.

Lottner S, Shehata M, Hickel R, Reichl F-X, Durner J. 2013. Effects of antioxidants on DNA-double strand breaks in human gingival fibroblasts exposed to methacrylate based monomers. Dental Materials. 29(9):991 998.

Lyapina M, Yaneva-Deliverska M, Deliversky J, Kisselova A. 2015. European and international standards on medical devices for dentistry. Journal of IMAB-Annual Proceeding Scientific Papers. 21(1):713-717.

Markowitz K, Moynihan M, Liu M, Kim S. 1992. Biologic properties of eugenol and zinc oxide-eugenol: a clinically oriented review. Oral Surgery, Oral Medicine, Oral Pathology. 73(6):729-737.

Mitchell DL, Synnott SA, VanDercreek JA. 1990. Tissue reaction involving an intraoral skin graft and CP titanium abutments: a clinical report. International Journal of Oral \& Maxillofacial Implants. 5(1).

Mjör IA. 1992. Problems and benefits associated with restorative materials: side-effects and long-term cost. Advances in dental research. 6(1):7-16.

Moharamzadeh K, Van Noort R, Brook IM, Scutt AM. 2007. Cytotoxicity of resin monomers on human gingival fibroblasts and HaCaT keratinocytes. dental materials. 23(1):40-44.

Murray PE, García Godoy C, García Godoy F. 2007. How is the biocompatibilty of dental biomaterials evaluated? Medicina Oral, Patología Oral y Cirugía Bucal (Internet). 12(3):258-266.

Mutoh N, Tani-Ishii N. 2011. A biocompatible model for evaluation of the responses of rat periapical tissue to a new zinc oxide-eugenol sealer. Dental materials journal. 30(2):176-182.

Mutter J, Naumann J, Walach H, Daschner F. 2005. Amalgam risk assessment with coverage of references up to 2005. Gesundheitswesen. 67(3):204-216.

Noda M, Wataha J, Kaga M, Lockwood P, Volkmann K, Sano H. 2002. Components of dentinal adhesives modulate heat shock protein 72 expression in heat-stressed THP-1 human monocytes at sublethal concentrations. Journal of dental research. 81(4):265-269.

Osman RB, Swain MV. 2015. A critical review of dental implant materials with an emphasis on titanium versus zirconia. Materials. 8(3):932-958.

Özcan M, Hämmerle C. 2012. Titanium as a reconstruction and implant material in dentistry: advantages and pitfalls. Materials. 5(9):1528-1545.

Parnia F, Yazdani J, Javaherzadeh V, Dizaj SM. 2017. Overview of nanoparticle coating of dental implants for enhanced osseointegration and antimicrobial purposes. Journal of Pharmacy \& Pharmaceutical Sciences.

20:148-160.

Parnia F, Yazdani J, Maleki Dizaj S. 2018. Applications of Mesenchymal Stem Cells in Sinus Lift Augmentation as a Dental Implant Technology. Stem cells international. 2018.

Parr GR, Gardner LK, Toth RW. 1985. Titanium: the mystery metal of implant dentistry. Dental materials aspects. Journal of Prosthetic Dentistry. 54(3):410-414. 
Peumans M, Kanumilli P, De Munck J, Van Landuyt K, Lambrechts P, Van Meerbeek B. 2005. Clinical effectiveness of contemporary adhesives: a systematic review of current clinical trials. Dental materials. 21(9):864-881.

Ponce Bravo S, Ledesma Montes C, Martínez-Rivera JI, Morales-Sánchez I. 2011. Toxicity test of a dental commercial composite in rats.

Raghavendra R, Naidu KA. 2009. Spice active principles as the inhibitors of human platelet aggregation and thromboxane biosynthesis. Prostaglandins, leukotrienes and essential fatty acids. 81(1):73-78.

Reichl F-X, Esters M, Simon S, Seiss M, Kehe K, Kleinsasser N, Folwaczny M, Glas J, Hickel R. 2006. Cell death effects of resin-based dental material compounds and mercurials in human gingival fibroblasts. Archives of toxicology. 80(6):370-377.

Reichl F-X, Simon S, Esters M, Seiss M, Kehe K, Kleinsasser N, Hickel R. 2006. Cytotoxicity of dental composite (co) monomers and the amalgam component $\mathrm{Hg} \mathrm{2+}$ in human gingival fibroblasts. Archives of toxicology. 80(8):465-472.

Reigosa M, Labarta V, Molinari G, Bernales D. 2008. Cytocompatibility, cytotoxicity and genotoxicity analyses of dental implants. BAG Journal of basic and applied genetics. 19(1):43-48.

Ribeiro D, Marques M, Salvadori DMF. 2005. Assessment of genetic damage induced by dental bleaching agents on mouse lymphoma cells by single cell gel (comet) assay. Journal of oral rehabilitation. 32(10):766771.

Ribeiro DA, Marques MEA, Salvadori DMF. 2006. Study of DNA damage induced by dental bleaching agents in vitro. Brazilian oral research. 20(1):47-51.

Ribeiro DA, Yujra VQ, DE MOURA CFG, Handan BA, Viana MDB, Yamauchi LY, Castelo PM, AGUIAR O. 2017. Genotoxicity Induced by Dental Materials: A Comprehensive Review. Anticancer research. 37(8):40174024.

Roberts SK, McAinsh M, Cantopher H, Sandison S. 2014. Calcium dependence of eugenol tolerance and toxicity in Saccharomyces cerevisiae. PloS one. 9(7):e102712.

Romanos GE, Weitz D. 2012. Therapy of peri-implant diseases. Where is the evidence? Journal of EvidenceBased Dental Practice. 12(3):204-208.

Rowan AN. 1997. The benefits and ethics of animal research. SCIENTIFIC AMERICAN-AMERICAN EDITION-. 276:79-79.

Sadoh D, Sharief M, Howard R. 1999. Case Study: Occupational exposure to methyl methacrylate monomer induces generalised neuropathy in a dental technician. British dental journal. 186(8):380.

Samiei M, Farjami A, Dizaj SM, Lotfipour F. 2016. Nanoparticles for antimicrobial purposes in Endodontics: A systematic review of in vitro studies. Materials Science and Engineering: C. 58:1269-1278.

Schmalz G. 2009. Resin-Based Composites. In: Schmalz G, Arenholt-Bindslev D, editors. Biocompatibility of Dental Materials. Berlin, Heidelberg: Springer Berlin Heidelberg; p. 99-137.

Schmalz G, Fan PL. 2009. Regulations and Standards. In: Schmalz G, Arenholt-Bindslev D, editors.

Biocompatibility of Dental Materials. Berlin, Heidelberg: Springer Berlin Heidelberg; p. 45-58.

Schmalz G, Galler KM. 2017. Biocompatibility of biomaterials-Lessons learned and considerations for the design of novel materials. Dental Materials. 33(4):382-393.

Schmalz G, Garhammer P. 2002. Biological interactions of dental cast alloys with oral tissues. Dental Materials. 18(5):396-406.

Schmid-Schwap M, Franz A, König F, Bristela M, Lucas T, Piehslinger E, Watts DC, Schedle A. 2009.

Cytotoxicity of four categories of dental cements. Dental Materials. 25(3):360-368.

Schweikl H, Spagnuolo G, Schmalz G. 2006. Genetic and cellular toxicology of dental resin monomers. Journal of dental research. 85(10):870-877.

Scott A, Egner W, Gawkrodger D, Hatton P, Sherriff M, Van Noort R, Yeoman C, Grummitt J. 2004. The national survey of adverse reactions to dental materials in the UK: a preliminary study by the UK Adverse Reactions Reporting Project. British dental journal. 196(8):471.

Şişman R, Aksoy A, Yalçın M, Karaöz E. 2016. Cytotoxic effects of bulk fill composite resins on human dental pulp stem cells. Journal of oral science. 58(3):299-305.

Smith DC. 1993. Dental implants: materials and design considerations. International Journal of Prosthodontics. $6(2)$.

SÖDERHOLM K-J, Mariotti A. 1999. BIS-GMA-based resins in dentistry: are they safe? The Journal of the American Dental Association. 130(2):201-209.

Stanford J. 1980. Recommended standard practices for cytotoxicity testing. FDI World Dental Federation in conjunction with International Standards Organization Dent J. 30:141-173. 
Swetha B, Mathew S, Murthy B, Shruthi N, Bhandi SH. 2015. Determination of biocompatibility: A review. Int Dent Med J Adv Res. 1(1):1-6.

SyeD M, ChopRa R, SaChDeV V. 2015. Allergic reactions to dental materials-a systematic review. Journal of clinical and diagnostic research: JCDR. 9(10):ZE04.

Tadin A, Gavić L, Galić N. 2016. Biocompatibility of Dental Adhesives. Adhesives-Applications and Properties. InTech.

Allergological aspects of implant biocompatibility. 5 th International CeramTec Symposium; 2000.

Thrivikraman G, Madras G, Basu B. 2014. In vitro/In vivo assessment and mechanisms of toxicity of bioceramic materials and its wear particulates. RSC Advances. 4(25):12763-12781.

Uçar Y, Brantley W. 2017. Biocompatibility of dental amalgams. Biocompatibility of Dental Biomaterials. Elsevier; p. 95-111.

Van Landuyt KL, Snauwaert J, De Munck J, Peumans M, Yoshida Y, Poitevin A, Coutinho E, Suzuki K, Lambrechts P, Van Meerbeek B. 2007. Systematic review of the chemical composition of contemporary dental adhesives. Biomaterials. 28(26):3757-3785.

Vazifehasl Z, Hemmati S, Zamanloo M, Dizaj SM. 2013. New Series of Dimethacrylate-Based Monomers on Isosorbide as a Dental Material: Synthesis and Characterization. International Journal of Composite Materials. 3(4):100-107.

Vera J, Siqueira JF, Ricucci D, Loghin S, Fernández N, Flores B, Cruz AG. 2012. One-versus two-visit endodontic treatment of teeth with apical periodontitis: a histobacteriologic study. Journal of endodontics. 38(8):1040-1052.

Walker D. 2004. Oral mucosal immunology: an overview. Annals-academy of Medicine Singapore. 33:27-30. Wellner P, Mayer W, Hickel R, Reichl F, Durner J. 2012. Cytokine release from human leukocytes exposed to silorane-and methacrylate-based dental materials. Dental Materials. 28(7):743-748.

Williams DF. 1981. Fundamental aspects of biocompatibility. Vol.1. CRC PressI Llc. Williams DF. 1999. The Williams dictionary of biomaterials. Liverpool University Press.

Zhao Y-y, Chu Q, Shi X-e, Zheng X-d, Shen X-t, Zhang Y-z. 2018. Toxicity testing of four silver nanoparticlecoated dental castings in 3-D LO2 cell cultures. Journal of Zhejiang University-SCIENCE B. 19(2):159-167.

Zhu L, Zhang J, Xiao L, Liu S, Yu J, Chen W, Zhang X, Peng B. 2015. Autophagy in resin monomer-initiated toxicity of dental mesenchymal cells: a novel therapeutic target of $\mathrm{N}$-acetyl cysteine. Journal of Materials

Chemistry B. 3(33):6820-6836. 


\section{Tables:}

\begin{tabular}{llll}
\hline Biocompatibility class & Definition in dentistry & $\begin{array}{l}\text { Examples of dental used } \\
\text { materials }\end{array}$ & $\begin{array}{l}\text { The main characteristic in } \\
\text { related to bone }\end{array}$ \\
\hline Biotolerant & $\begin{array}{l}\text { Materials that are separated } \\
\text { from bone tissue by a layer of } \\
\text { fibrous tissue. }\end{array}$ & $\begin{array}{l}\text { Cements based on poly } \\
\text { (methyl methacrylate), } \\
\text { stainless steels, Cobalt } \\
\text { alloys }\end{array}$ & Distance osteogenesis \\
Bioinert & $\begin{array}{l}\text { Materials that possess the } \\
\text { property of establishing } \\
\text { chemical bonds with bone } \\
\text { tissue (osseointegration). }\end{array}$ & $\begin{array}{l}\text { Titanium, zirconium, } \\
\text { aluminum, carbon }\end{array}$ & $\begin{array}{l}\text { Direct contact to bony tissue, } \\
\text { direct contact to osteogenesis }\end{array}$ \\
Bioactive & $\begin{array}{l}\text { Materials may show direct } \\
\text { contact with the adjacent bone } \\
\text { tissue without chemical } \\
\text { reactions between the implant } \\
\text { and the tissue. }\end{array}$ & $\begin{array}{l}\text { Hydroxy apatite, calcium } \\
\text { carbonate, calcium } \\
\text { phosphate, glass ceramics }\end{array}$ & $\begin{array}{l}\text { Bonding to bony tissue, } \\
\text { bonding osteogenesis }\end{array}$ \\
\hline
\end{tabular}

Table 1 Classification of dental used materials based on biocompatibility (Williams 1981; Albrektsson et al. 1983).

Poly (methyl methacrylate): also known as acrylic or acrylic glass is a commonly used material in modern dentistry, particularly in the fabrication of dental prosthetics, artificial teeth, and orthodontic appliances. 


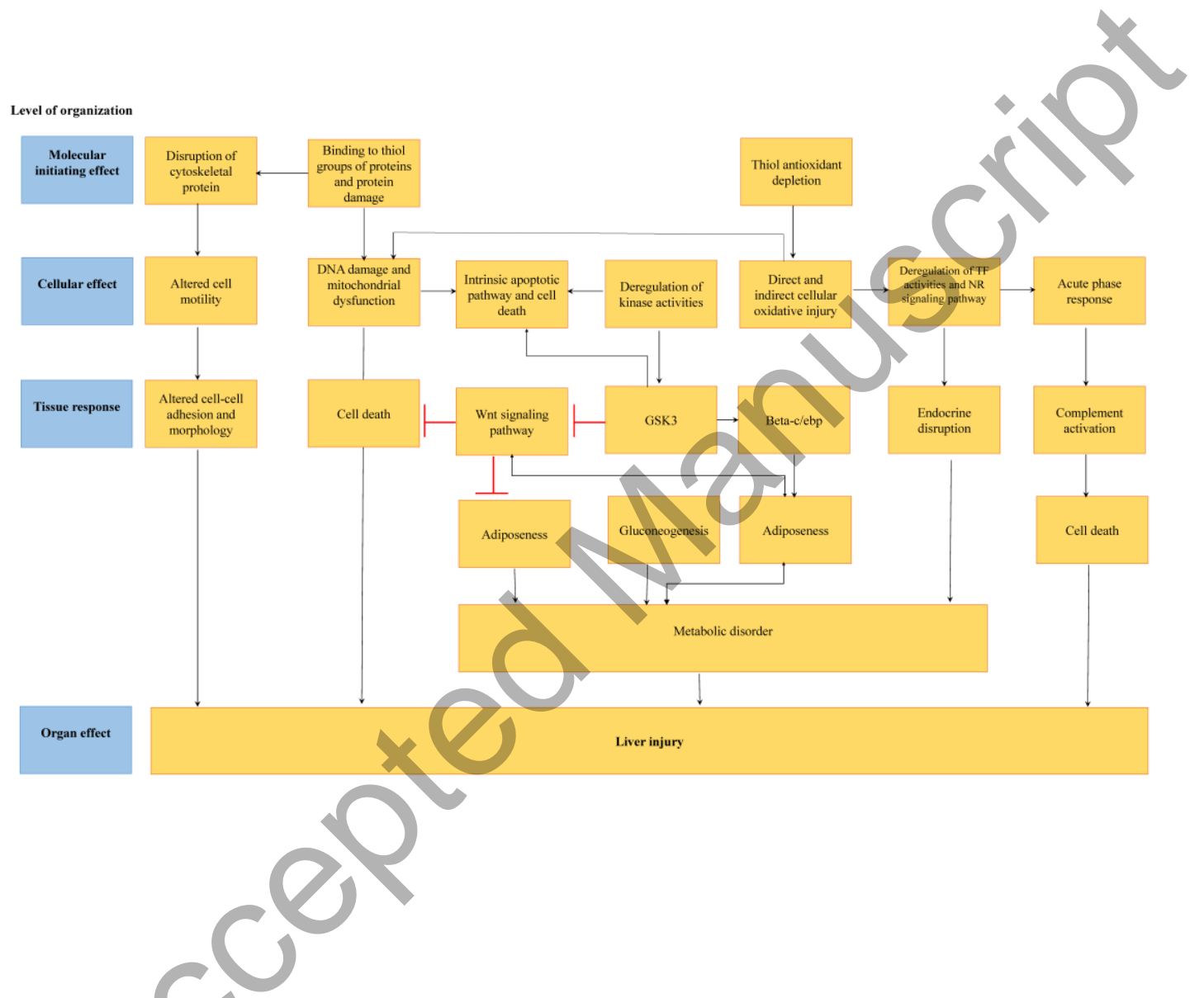

Figure 1. Mercury induced cytotoxicity and related signaling pathways. Mercury is the main component of amalgam used to fill cavities in dentistry. It induces different signaling pathways leading to cell death, DNA damage and liver dysfunction. 


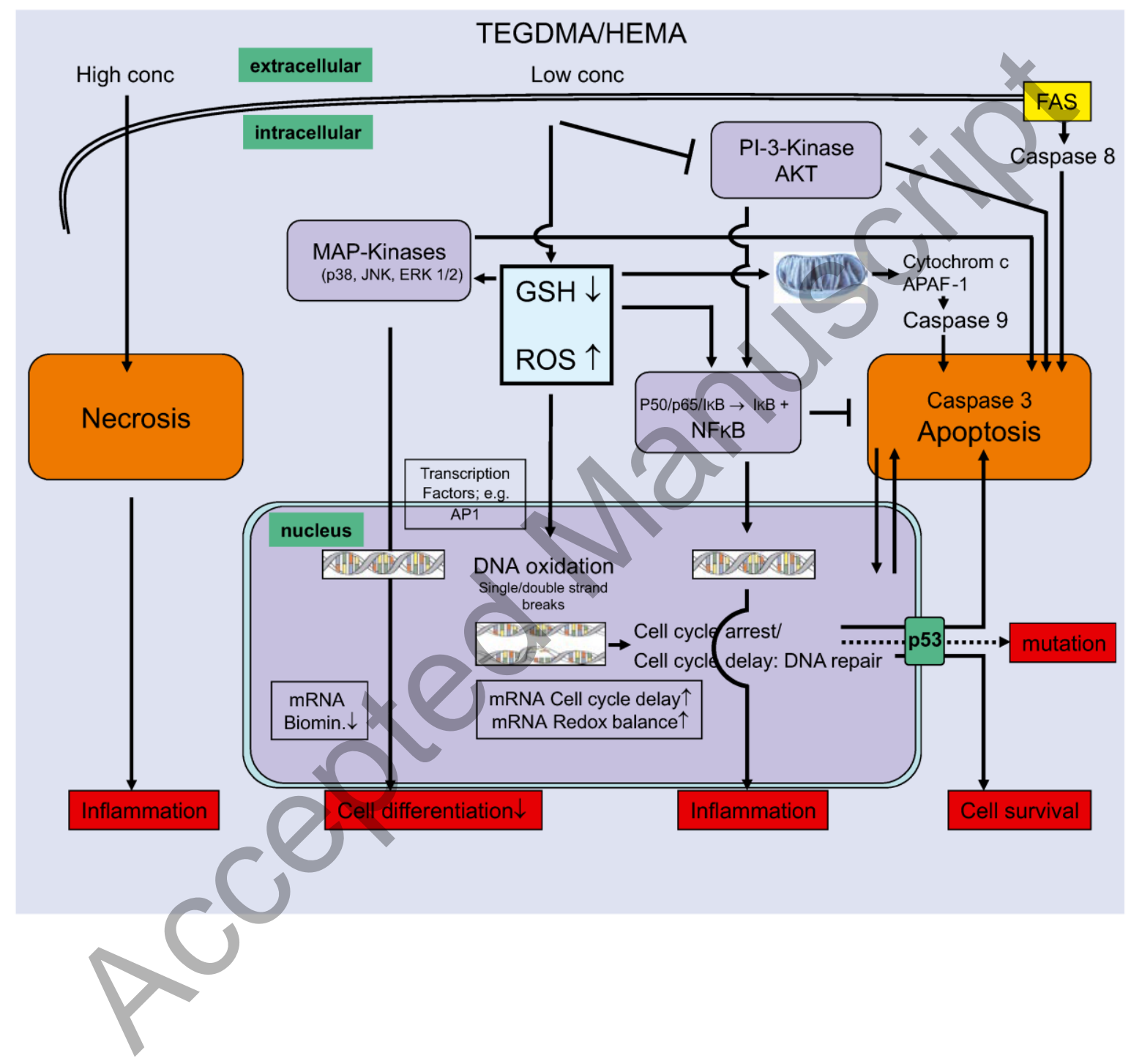

Figure 2. The possible influence of non-polymerized monomers released from dental composite resins in cell function and metabolism (adopted from ref (Schmalz 2009) 


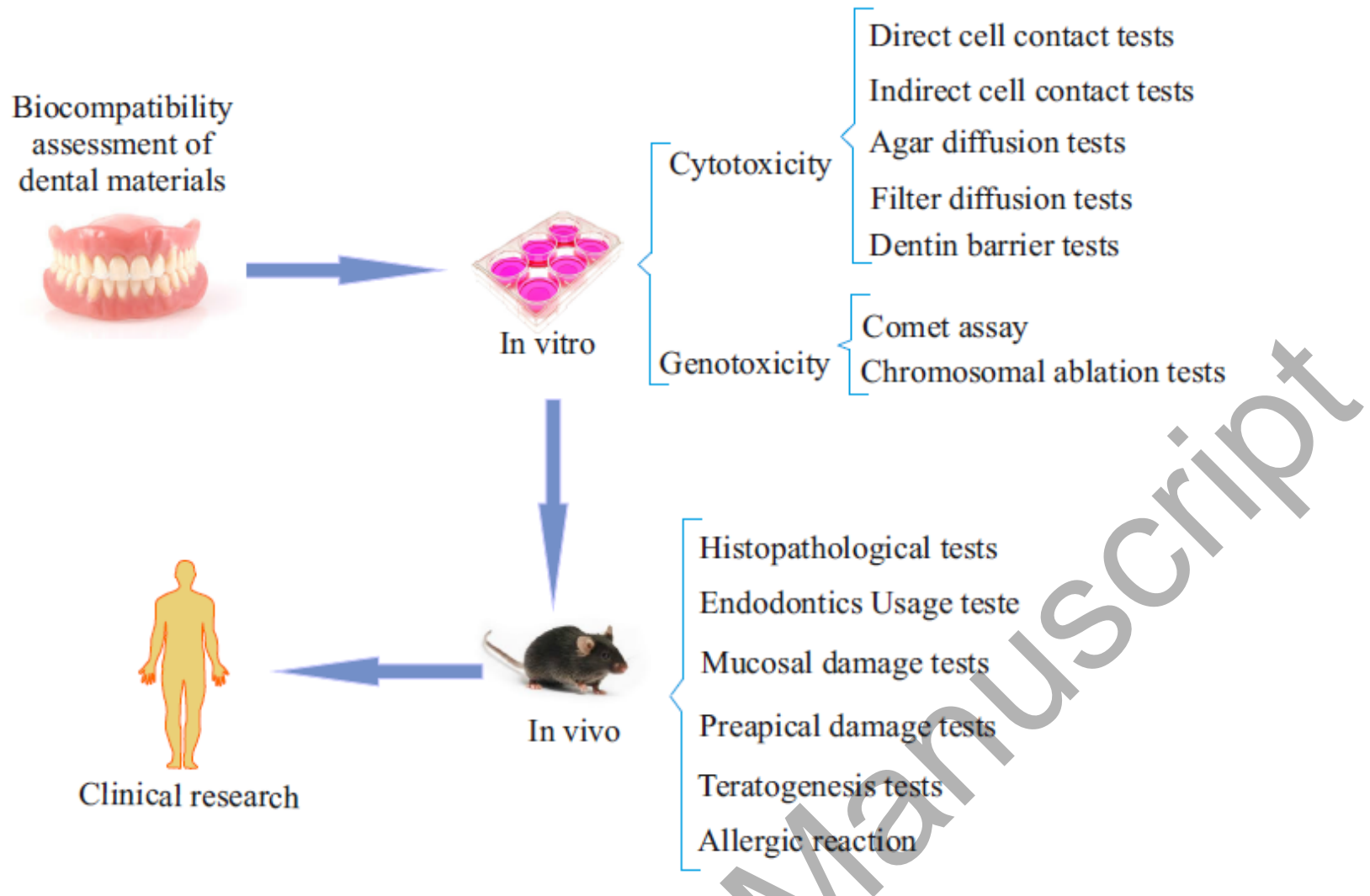

Figure 3. Different steps in evaluation of the toxicity and biocompatibility of dental materials. 